Supplementary information for:

\title{
Liposomal Fe(III) Macrocyclic Complexes with Hydroxypropyl Pendants as MRI Probes
}

Samira M. Abozeid, Md Saiful I. Chowdhury, Didar Asik, Joseph A. Spernyak, and Janet R.

Morrow*

Corresponding author's email: jmorrow@buffalo.edu

\section{Table of Contents}

Synthesis of ligands and characterization of complexes.......................................... 2

$\mathrm{r}_{1}$ relaxivity values for 3 different sizes of LipoA at different field strengths...................3

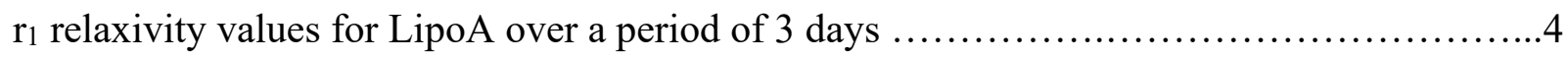

CEST spectra of the paramagnetic LipoA ...............................................

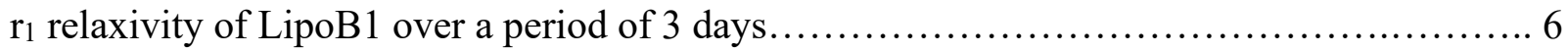

$\mathrm{r}_{1}$ relaxivities of paramagnetic liposomes on a per nanoparticles basis ......................6

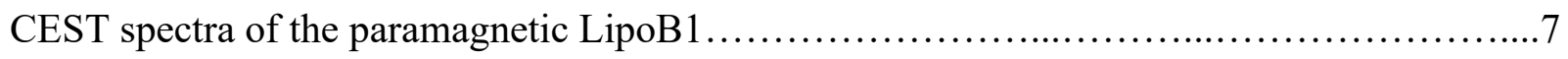

Relaxivity of LipoA and LipoB1 in water versus mouse serum .............................. 8

Relaxivity of LipoA and LipoB1 at different temperatures................................

Dynamic light scattering characterization of liposomes ............................... 10

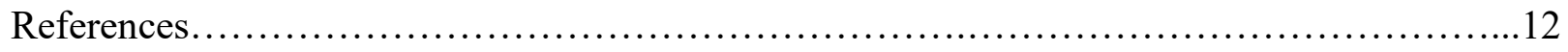




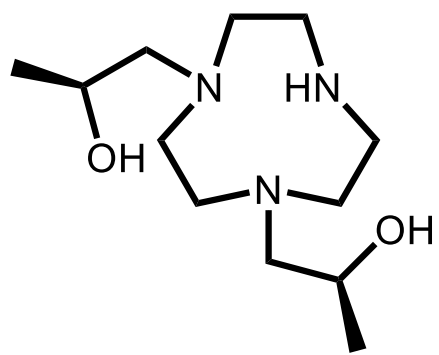

1 equivalent 2-hexadecyloxirane DIPA, ethanol, reflux

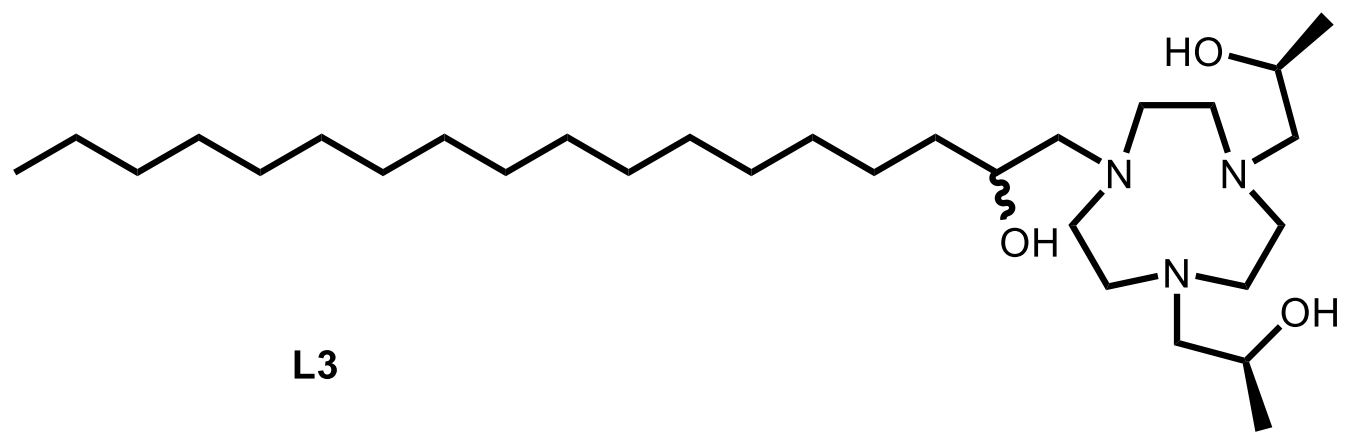

Scheme S1. Synthesis of ligand for amphiphilic complex, L3

Table S1. Solution effective magnetic moments by using Evans method.

\begin{tabular}{|l|l|l|}
\hline Complex & $\mathrm{Fe}(\mathrm{L} 1)$ & $\mathrm{Fe}(\mathrm{L} 2)$ \\
\hline$\mu_{\text {eff }}$ & $5.94 \pm 0.3$ & $5.90 \pm 0.5$ \\
\hline
\end{tabular}




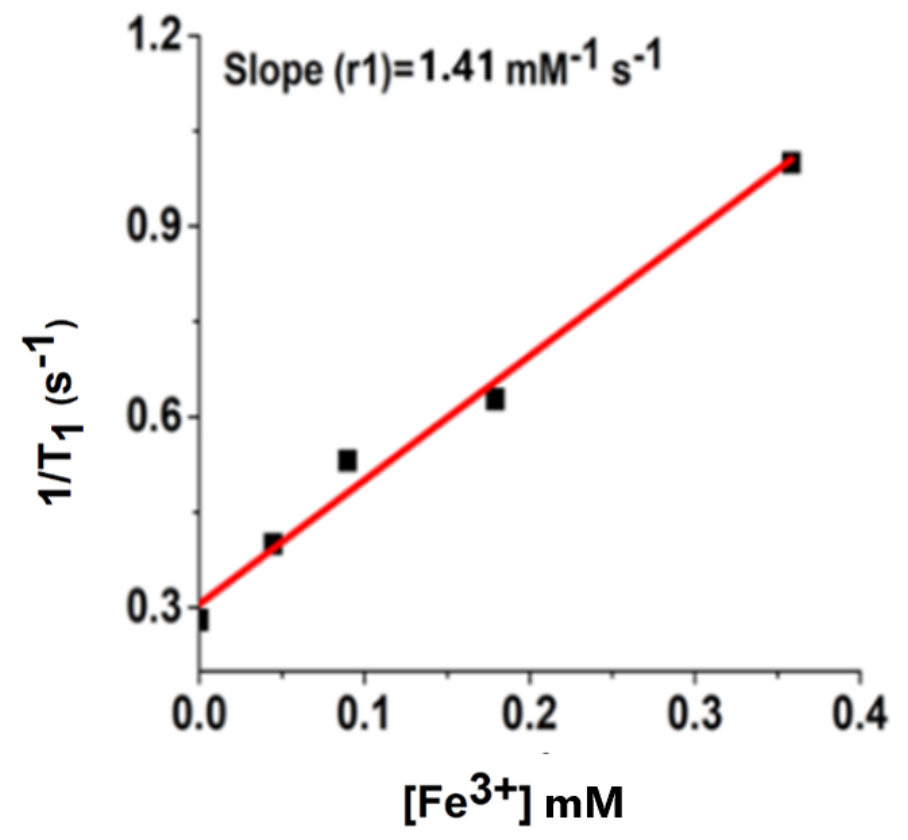

Figure S1. Plot of $\mathrm{I} / \mathrm{T}_{1}$ as a function of $\mathrm{Fe}(\mathrm{L} 1)$ concentration at $37^{\circ} \mathrm{C}, 9.4 \mathrm{~T}$.

Table S2: $r_{1}$ relaxivity values (per iron) for 3 different sizes of LipoA at different field strengths, at $37^{\circ} \mathrm{C}$ and $\mathrm{pH} 6.8-7.2$.

\begin{tabular}{|l|l|l|l|}
\hline & $\mathbf{r}_{\mathbf{1}}\left(\mathbf{m M}^{-1} \mathbf{s}^{-1}, \mathbf{1 . 4 T}\right)$ & $\mathbf{r}_{\mathbf{1}}\left(\mathbf{m M}^{-1} \mathbf{s}^{-1}, \mathbf{9 . 4 T}\right)$ & Liposome size/PDI \\
\hline LipoA, 130 & $0.92-1.0$ & 1.2 & \\
\hline LipoA, 210 nm & $0.79-0.84$ & 0.88 & $130 / 0.056$ \\
\hline LipoA, 380 nm & 0.50 & 0.67 & $208 / 0.151$ \\
\hline
\end{tabular}




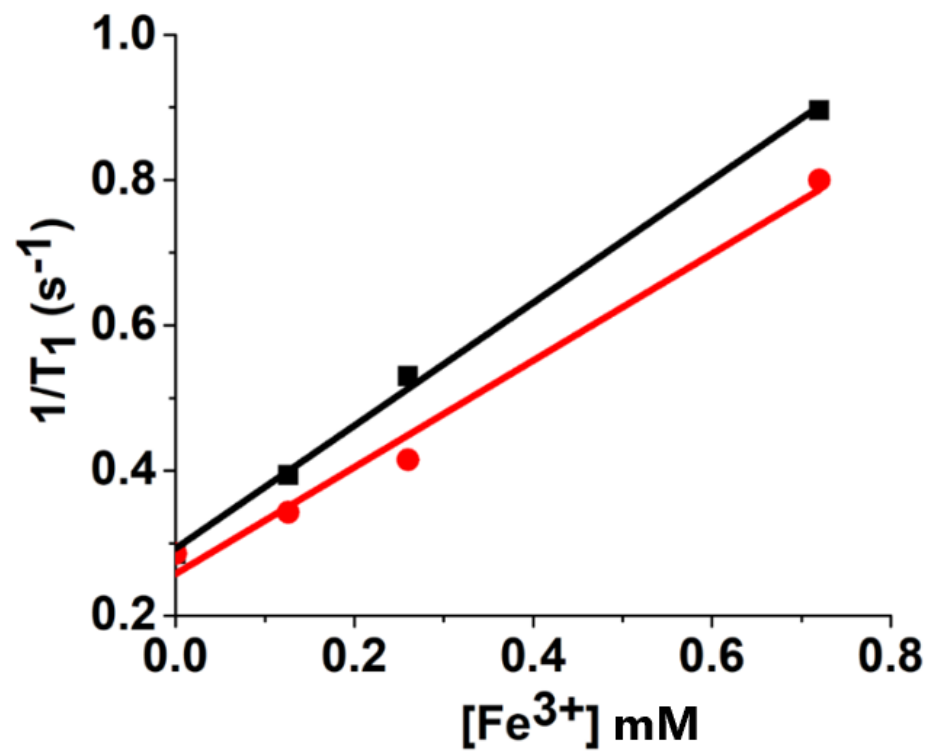

Figure S2. Example of a plot to measure $\mathrm{r}_{1}$ relaxivity of LipoA, $1.4 \mathrm{~T}, 34^{\circ} \mathrm{C}, \mathrm{pH} 6.8$ against $\mathrm{Fe}$ $(\mathrm{mM})$ concentration. The red line is for data taken three days after preparation of the liposomes. Slope of original experiment (black squares) is 0.84 and after 3 days (red circle) is 0.73 . 


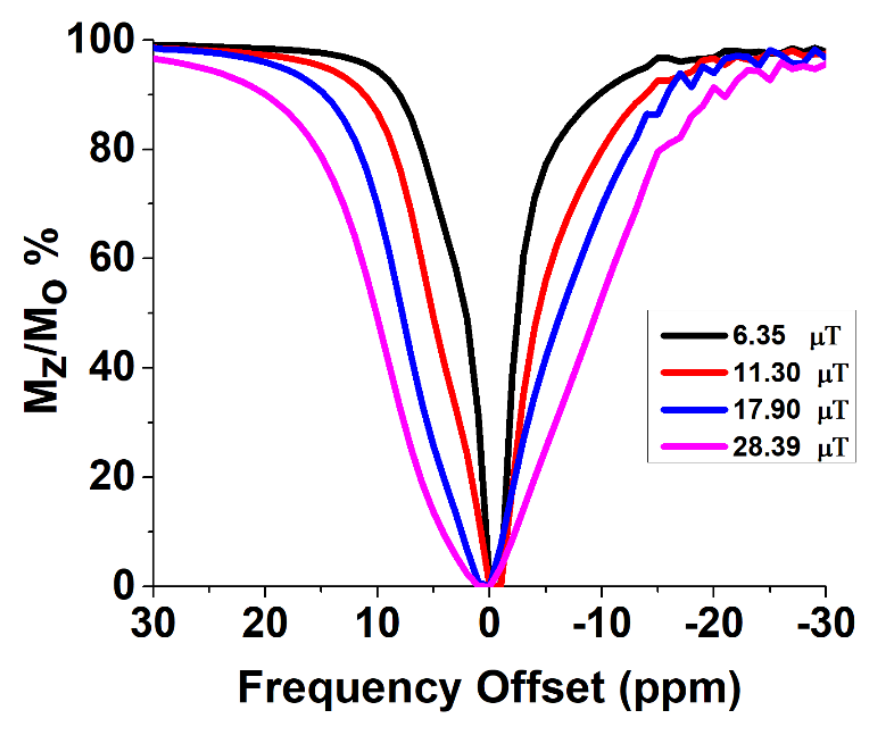

Figure S3. Z-spectra of LipoA at $37{ }^{\circ} \mathrm{C}$, $\mathrm{pH} 6.8,11.7 \mathrm{~T}$ at $600 \mathrm{mOsm} / \mathrm{L}$, and different saturation pulse powers.

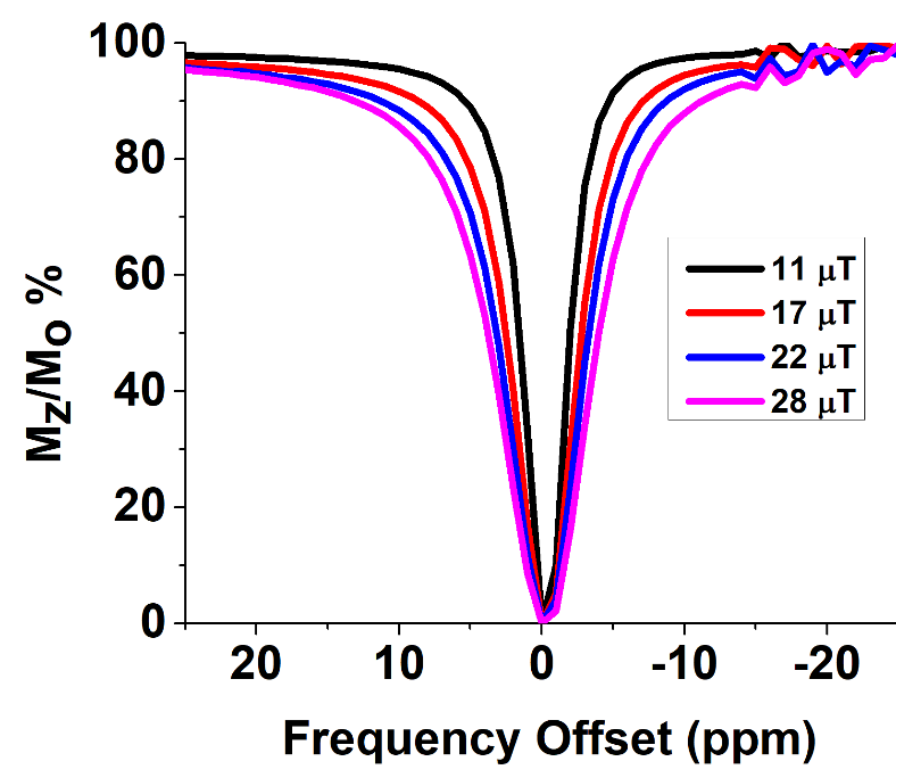

Figure S4. Z- spectra of empty liposomes (no paramagnetic centers), at $37{ }^{\circ} \mathrm{C}, 11.7 \mathrm{~T}$, at different saturation pulse powers. 

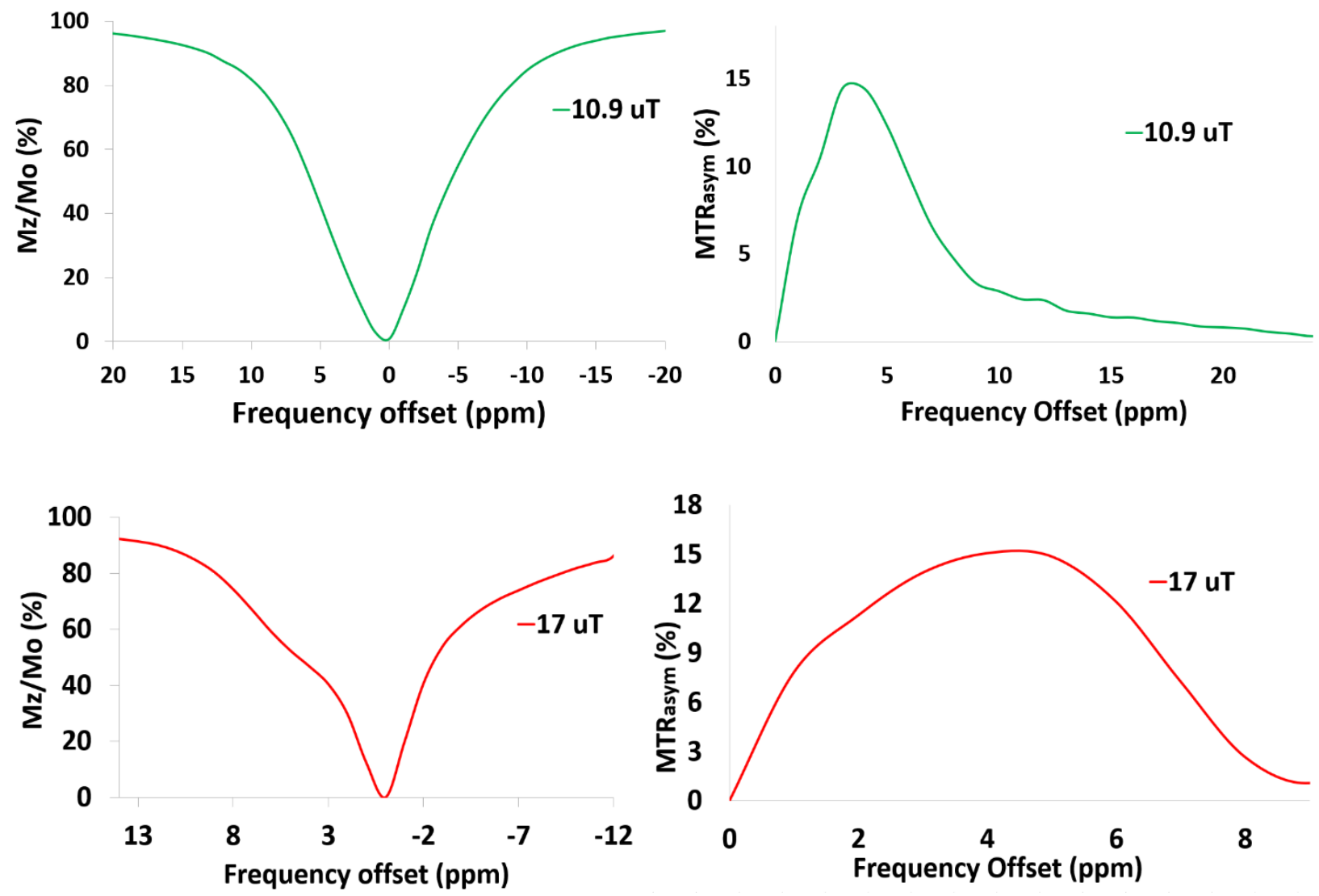

Figure S5. Z- spectra (left) and magnetization transfer asymmetry (right). Top: LipoB1 at $37^{\circ} \mathrm{C}$, $\mathrm{pH}$ 7.2, $1200 \mathrm{mOsm} / \mathrm{L}, 11.7 \mathrm{~T}$. Bottom: LipoA at $1200 \mathrm{mOsm} / \mathrm{L}$, at $37^{\circ} \mathrm{C}, \mathrm{pH}$ 7.2. Equation for MTR $_{\text {asym }}(\%)$ is given below-

$$
\operatorname{MTR}_{\text {asym }}(\Delta \omega) \%=\frac{M_{\text {sat }}(-\Delta \omega)-M_{\text {sat }}(\Delta \omega)}{M_{o}} \times 100
$$




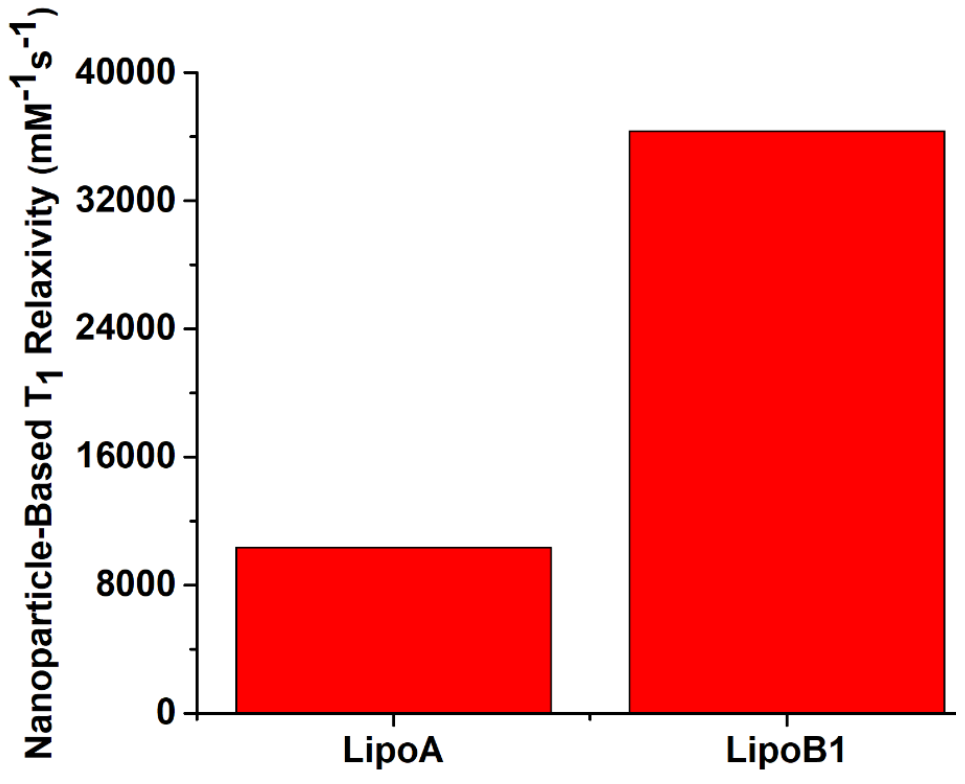

Figure S6. The $r_{1}$ relaxivity of liposomal-Fe formulations on a per nanoparticle basis. The number of particles was calculated based on the lipid concentration and the average size of the liposome as determined by DLS.

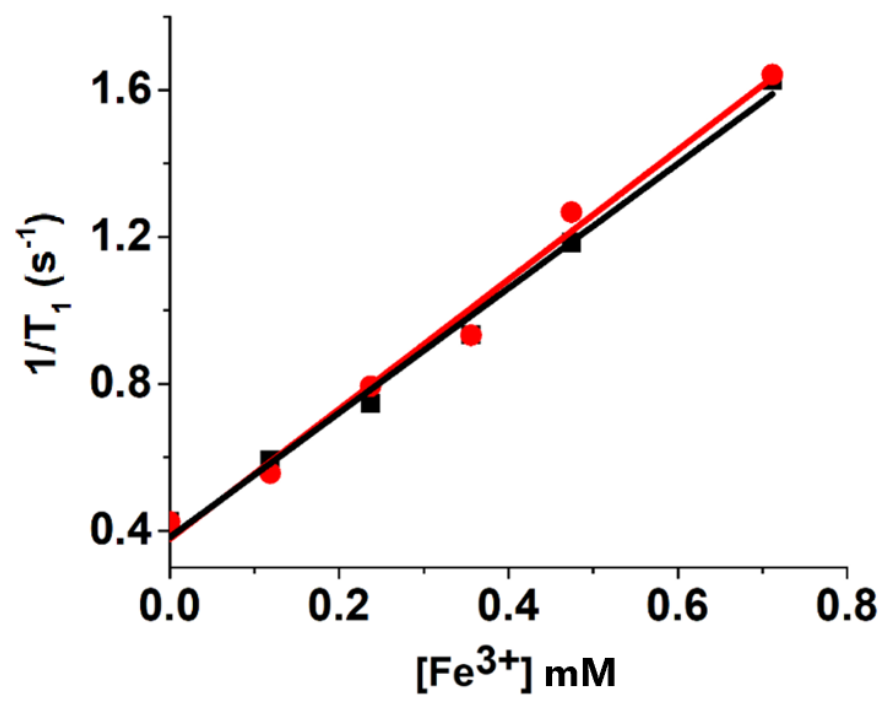

Figure S7. Example of plot to measure the $\mathrm{r}_{1}$ relaxivity of LipoB1, $1.4 \mathrm{~T}, 34{ }^{\circ} \mathrm{C}, \mathrm{pH}$ 6.8. The red line connects points taken three days after preparation of the liposomes. Slope of original experiment (black circles) is 1.7 and after 3 days (red squares) is 1.7 . 


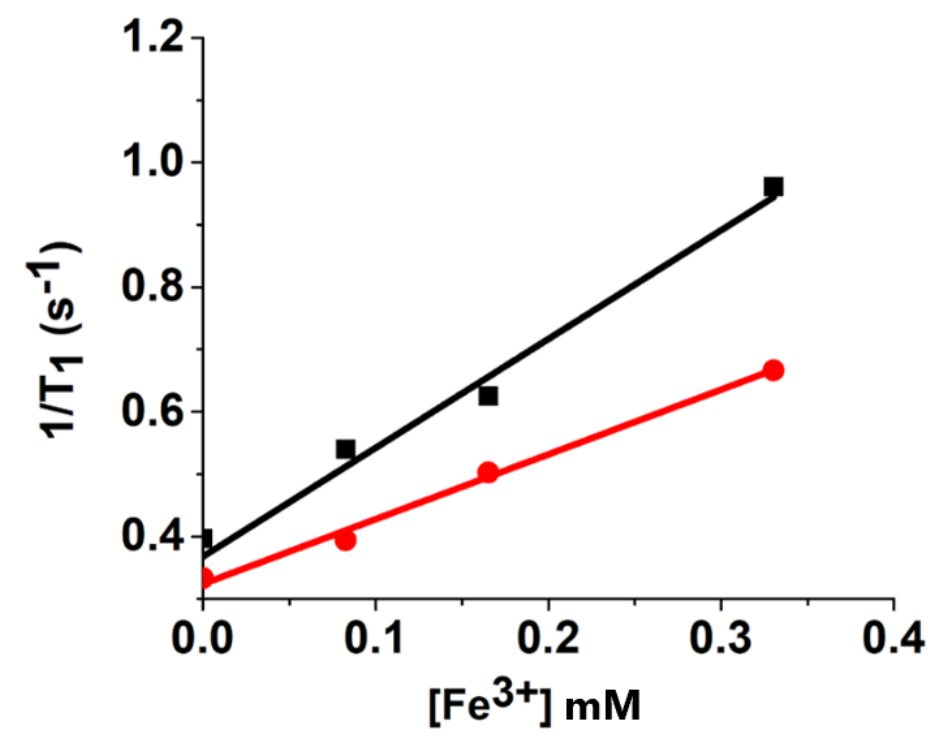

Figure S8. Plot to measure the relaxivity of LipoA in presence (black) and absence (red) of mouse serum, at $1.4 \mathrm{~T}, 34{ }^{\circ} \mathrm{C}$. $\left(\mathrm{r}_{1}\right.$ with serum $=1.7 \mathrm{mM}^{-1} \mathrm{~s}^{-1}, \mathrm{r}_{1}$ without serum $\left.=1.0 \mathrm{mM}^{-1} \mathrm{~s}^{-1}\right)$.

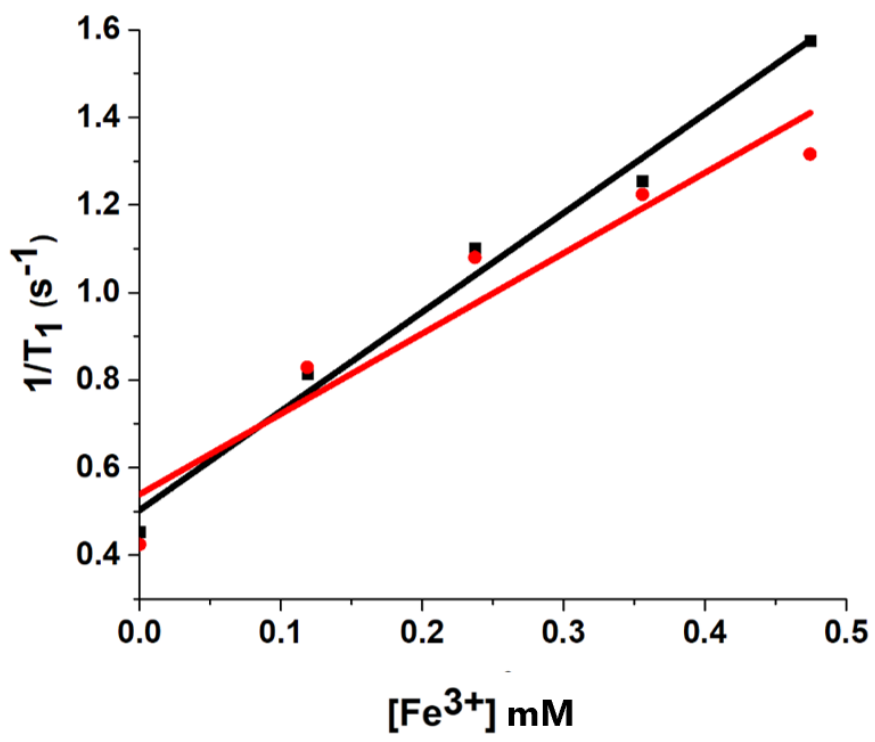

Figure S9. Plot to measure the relaxivity of LipoB1 in presence and absence of mouse serum, at $1.4 \mathrm{~T}, 34{ }^{\circ} \mathrm{C}$. The slope ( $\left.\mathrm{r}_{1}\right)$ with serum is $2.3 \mathrm{mM}^{-1} \mathrm{~s}^{-1}$ (black line), $\mathrm{r}_{1}$ with serum after 3 days is $1.8 \mathrm{mM}^{-1} \mathrm{~s}^{-1}$ (red line). 

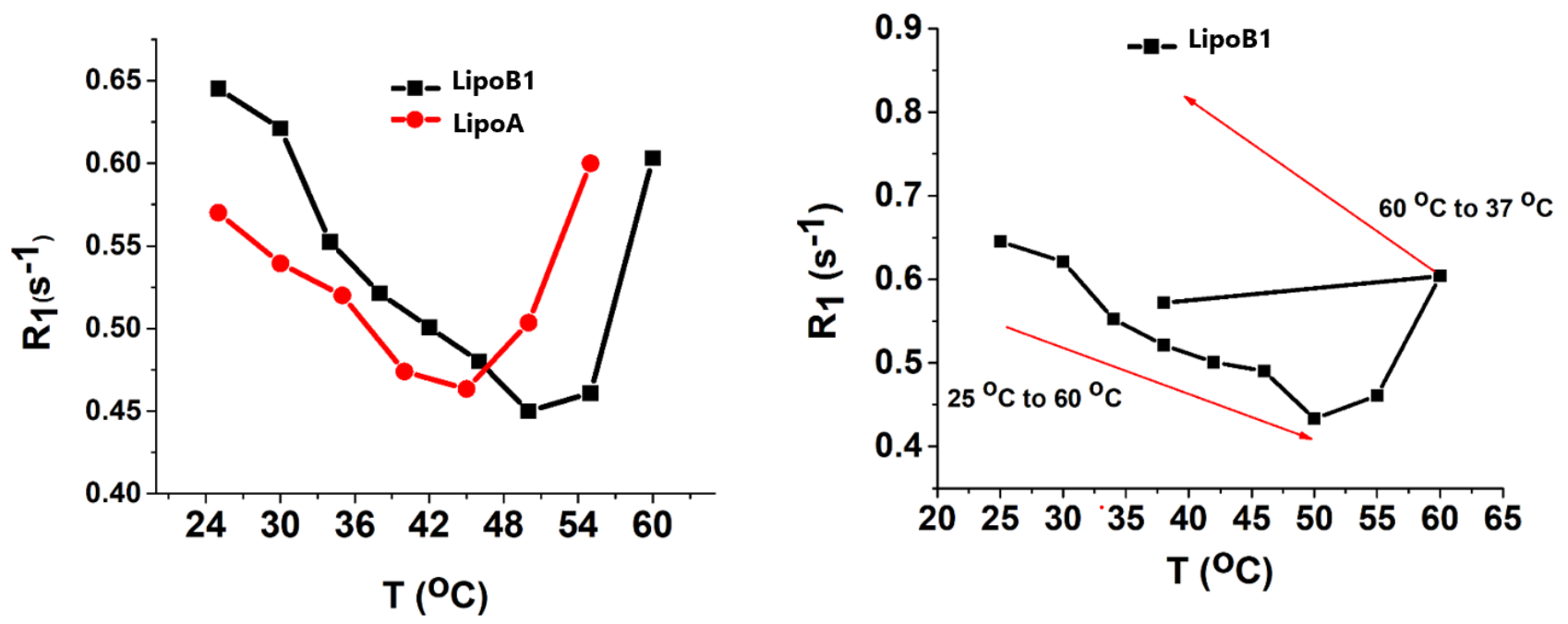

Figure S10. Plots of the $\mathrm{R}_{1}$ rate constant versus temperature for lipoB1 and LipoA at 9.4 T. 


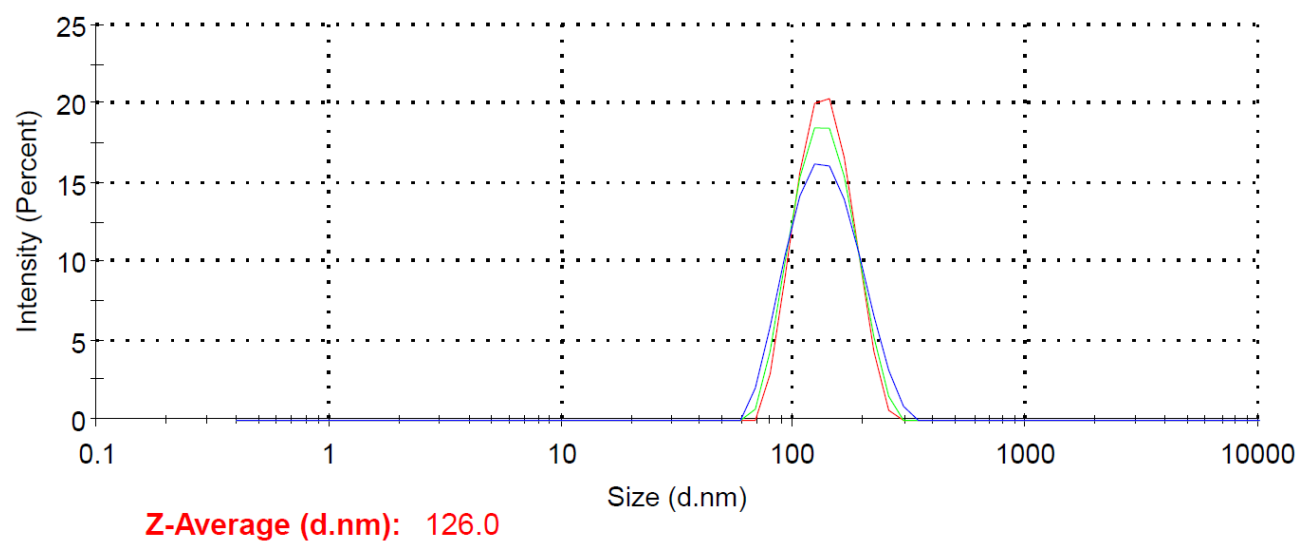

Pdl: 0.113

Figure S11. Size distribution by intensity of LipoA using dynamic light scattering.

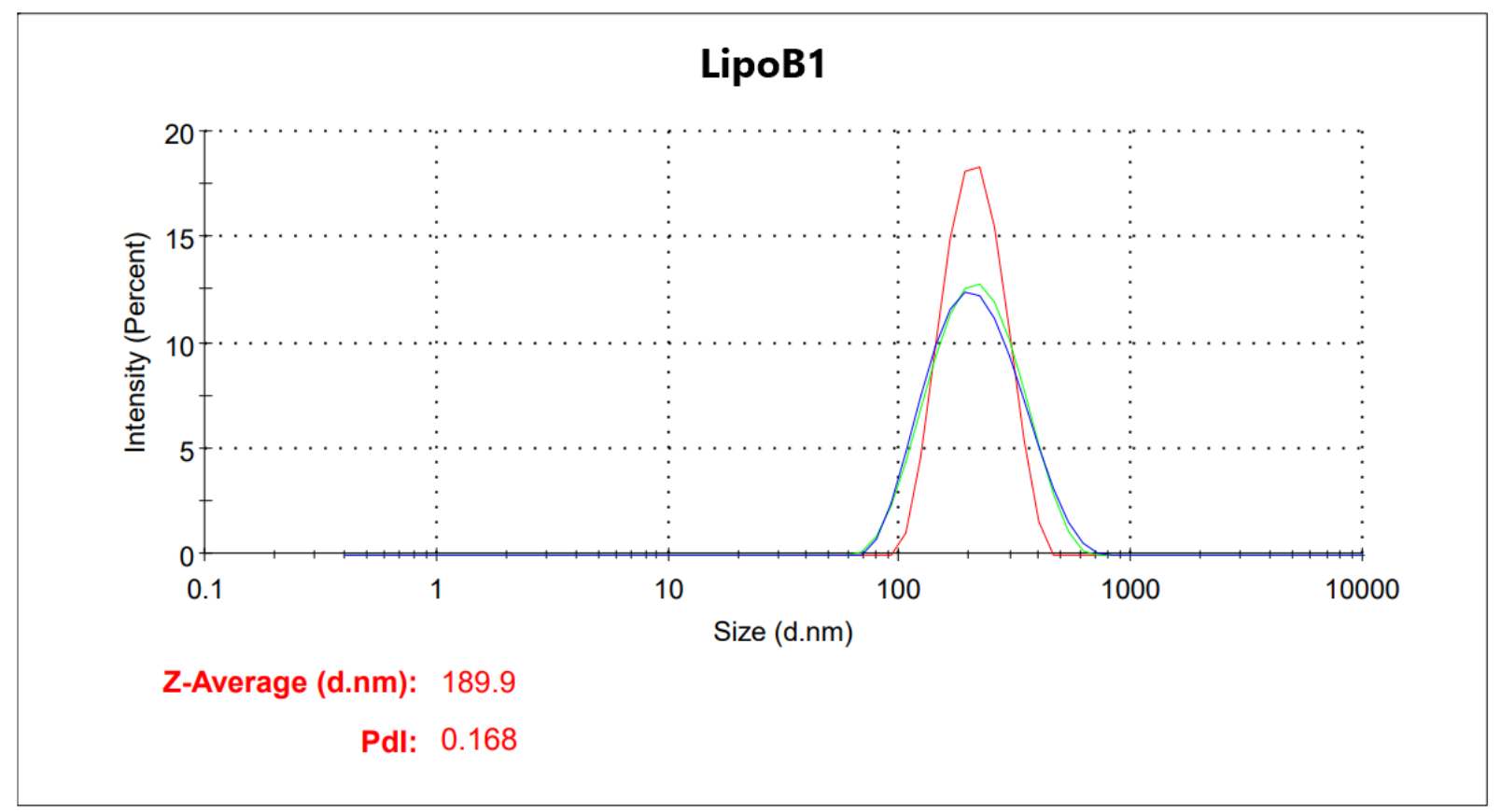

Figure S12. Size distribution by intensity of LipoB1 using dynamic light scattering. 


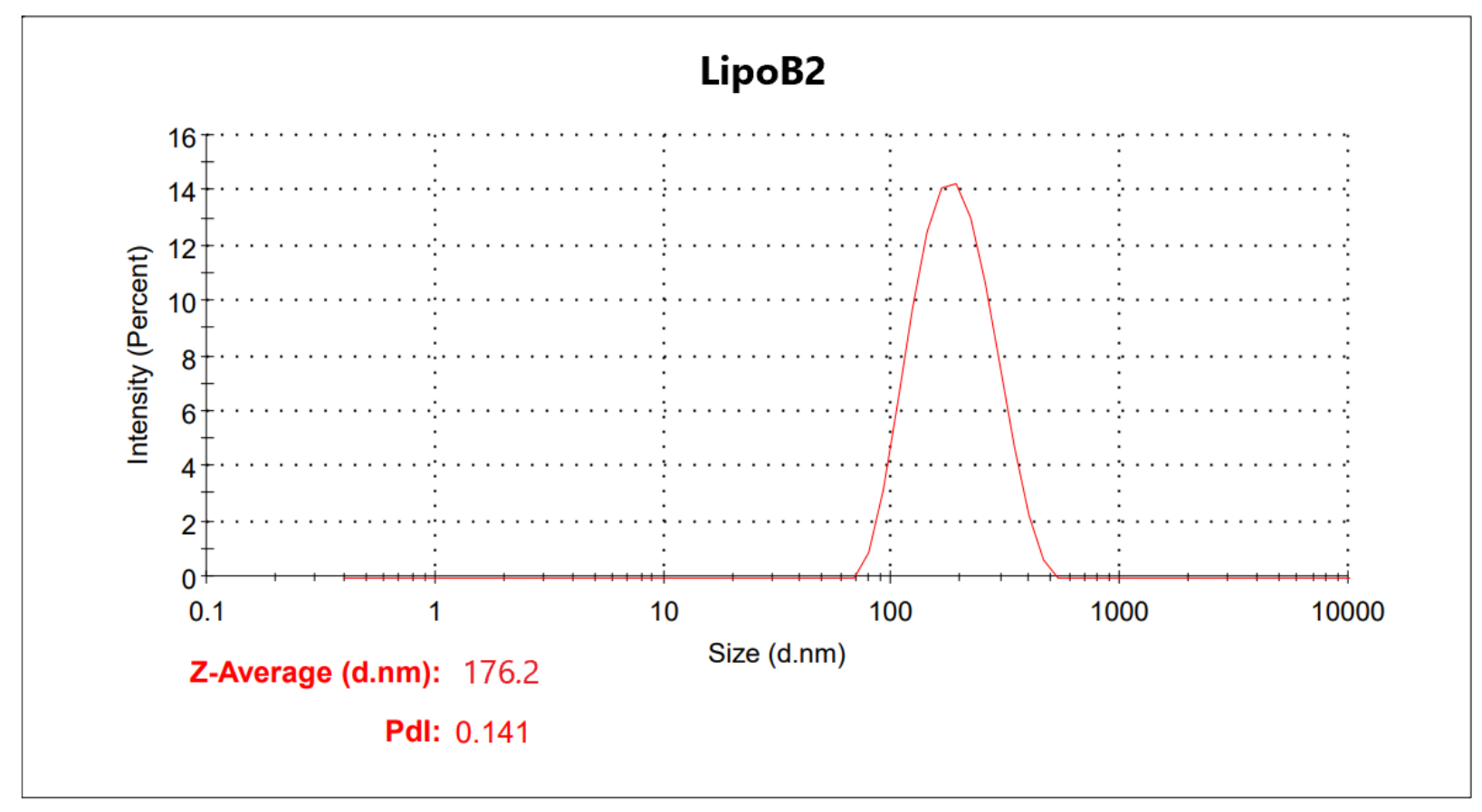

Figure S13. Size distribution by intensity of LipoB2 using dynamic light scattering.
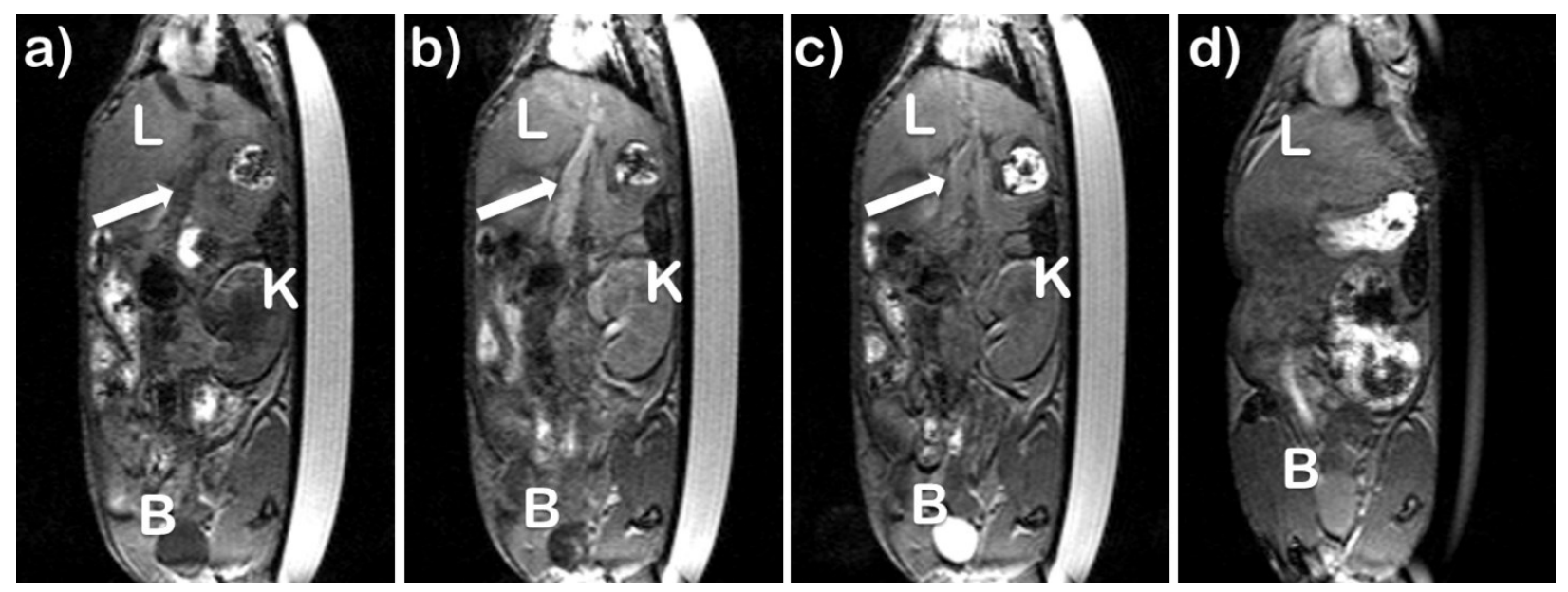

Figure S14. $T_{1}$-weighed, spoiled gradient echo MR images before injection of LipoB1 (a), as well as immediately after (b), 45 minutes after (c) and $4 \mathrm{~h}$ after injection (d) at a dose of $25 \mu \mathrm{mol}$ $[\mathrm{Fe}] / \mathrm{kg}$. Enhancement within the first hour was observed in the liver (L), kidney (K), urinary bladder (B), and blood vessel (arrow). At $4 \mathrm{~h}$ post-injection, residual enhancement was seen in the bladder and kidney (not shown), indicating continuing renal clearance. 


\section{References}

1. Weeks, J. M.; Buntine, M. A.; Lincoln, S. F.; Tiekink, E. R. T.; Wainwright, K. P., Diastereomeric discrimination in 1,4,7-tris((S)-2-hydroxypropyl)-1,4,7-triazacyclononane and its lithium(I), sodium(I) and zinc(II) complexes. J. Chem Soc, Dalton Trans 2001, (14), 2157-2163. 2. Abozeid, S. M.; Snyder, E. M.; Lopez, A. P.; Steuerwald, C. M.; Sylvester, E.; Ibrahim, K. M.; Zaky, R. R.; Abou-El-Nadar, H. M.; Morrow, J. R., Nickel(II) Complexes as Paramagnetic Shift and paraCEST Agents. Eur J Inorg Chem 2018, 2018 (18), 1902-1908.

3. Abozeid, S. M.; Snyder, E. M.; Tittiris, T. Y.; Steuerwald, C. M.; Nazarenko, A. Y.; Morrow, J. R., Inner-Sphere and Outer-Sphere Water Interactions in Co(II) paraCEST Agents. Inorg Chem 2018, 57 (4), 2085-2095.

4. $\quad$ Snyder, E. M.; Asik, D.; Abozeid, S. M.; Burgio, A.; Bateman, G.; Turowski, S. G.; Spernyak, J.; Morrow, J. R., A class of Fe(III) macrocyclic complexes with alcohol donor groups as effective T1 MRI contrast agents. Angew Chem. Int. Ed. 2020, (59), 2414-2419.

5. Piguet, C., Paramagnetic Susceptibility by NMR: The "Solvent Correction" Removed for Large Paramagnetic Molecules. J. Chem. Educ. 1997, 74 (7), 815-816.

6. Evans, D. F., 400. The determination of the paramagnetic susceptibility of substances in solution by nuclear magnetic resonance. J. Chem. Soc. 1959, 2003-2005.

7. Abozeid, S. M.; Asik, D.; Sokolow, G. E.; Lovell, J. F.; Nazarenko, A. Y.; Morrow, J. R., Co(II) Complexes as Liposomal CEST Agents. Angew. Chem. Int. Ed. 2020, (59), 1209312097.

8. Asik, D.; Smolinski, R.; Abozeid, S. M.; Mitchell, T. B.; Turowski, S. G.; Spernyak, J. A.; Morrow, J. R., Modulating the Properties of Fe(III) Macrocyclic MRI Contrast Agents by Appending Sulfonate or Hydroxyl Groups. Molecules 2020, 25 (10), 2291. 